In theory the domestic supervisor should show the domestic the work that is required in the ward and how to do it, and she should then inspect the work afterwards to ensure that it has been done properly. If the supervisor is young and inexperienced and the domestics are seasoned salts, the first attempt to criticise the quality of shoddy work may be followed by a walk-out or even a strike. Delegation downwards is fine in theory but what happens if accountability upwards is ignored?

The clinical ward sister is still the pivot of the ward and she knows best how to deploy the domestic as well as nursing staff in her ward. If the domestic staff were answerable to her, three layers of administrators could be eliminated. This would save cash, improve the quality of care for the patient, and allow the ward sister to spend her time nursing patients instead of phoning administrators begging them to administrate. Clinicians have good evidence-their memories of pre-Salmon days-that this prescription is right. The obligation is on those who disagree to find another way of putting matters right-for something has to be done.

\section{Does Britain need an academy of medicine?}

In 1972 the Americans set up an Institute of Medicine within the US National Academy of Sciences, and already it is.making impressive contributions to the development of health care. This year, for example, the publication of Medical Technology and the Health Care System by the Academy and Healthy People, a review of the possibilities of prevention, by the Department of Health, Education, and Welfare has shown the institute's potential. Its membership is limited and selected-not all medical-and subject to both age and time limits. The academy appoints a whole-time president, its staff is small, while it has had the benefit of substantial core funds from the major foundations concerned with health. The institute undertakes assignments under contract, mainly from Government and usually through special committees. Such a system would not be easy to develop here, but Britain does lack a similar authoritative source of advice-to the Government and other bodies - on health, as opposed to medical science.

The Medical Research Council is a highly regarded source of advice on biomedical research, and the Royal Colleges and faculties can speak on their various specialties. Standing advisory committees have been used, either for overall advice or for detailed assessments of subjects such as vaccination and immunisation. The Royal Colleges have produced outstanding reports on smoking, fluoridation, alcoholism, and relations between the professions; and the BMA provides valuable advice to governments and the community. It is no disrespect to these important contributions for the $B M \mathcal{F}$ to suggest that more is now needed. Perhaps the Royal Commission's suggestion of an institute for health services research stemmed partly from its discovery that there is no generally recognised source of medical and allied opinion on many of the problems that need to be faced in the NHS.

A consortium of existing Royal Colleges, faculties and specialty associations, and the BMA, which will all continue for their proper purposes, might form the basis of the British Academy of Medicine which has been advocated at various times, but it would need to develop a degree of independence of the parent bodies which would not admit of a veto by one of them. Substantial funds would be needed if staff of high quality were appointed, and most of the existing bodies are deeply committed with separate and expensive headquarters to maintain.

It is, indeed, the multiplicity of British medical institutions that has encouraged each of them to emphasise its sectional, specialist role. In accordance with its members' wishes, the BMA is now identified more closely with trade-union style negotiations on behalf of doctors, though its professional activities remain extensive. The individual Royal Colleges, now so much more numerous than before the second world war, each speak for a narrow segment of medical opinion. From the nature of their constitutions and history the colleges tend to exclusiveness, seniority, and identification with the teaching centres. Medicine now changes so rapidly in ways which affect the disciplines across the board that the case for establishing a body which can propound an authoritative medical view, taking account of scientific and other health professional opinion, becomes stronger with each passing year. The profession did combine to establish the Councils for Postgraduate Education with Government support, including funds; it has for much longer combined in the General Medical Council at its own expense; and the BMA launched a brave but brief initiative in the 'sixties with its Planning Unit. But surely the time has come for doctors to find a way of combining for these wider needs.

\section{Caring for all our children}

Christmas is a time for families to come together, viewing each other cheerfully or with ill-concealed loathing across the dinner table. Each generation of parents seems to have found its adolescent children a cause for anxiety, and even occasional despair, but the level of concern is probably highest at timessuch as the 20 th century-of rapid social change. The present generation has had its anxieties further exacerbated by the mushroom growth of sociology and behavioural psychology and the proliferation of reports on and studies of adolescents and their problems. Yet opinions about the up-and-coming generation are still the same as those found among the Ancient Greeks or Romans ; some experts believe that the young have never been more alienated from their parents' values, while others take an optimistic view, seeing hope in the originality and enthusiasm of youth.

Among the many strident voices claiming to make authoritative judgments on adolescence Professor Michael Rutter's assessments have stood out for their objectivity and their reliance on research studies rather than intuitive opinions; and he has now brought together his own and other findings in the 1979 Rock Carling Fellowship. ${ }^{1}$ For most teenagers adolescence is not, says Rutter, a period of either psychological disturbance or social alienation. Though alarmist views are unwarranted, some adolescent problems are becoming more frequent, and delinquency, attempted suicide, anorexia nervosa, alcoholism, and drug abuse have become the psychological disorders characteristic of the teenage years. The effect of these disorders is felt on society at large as well as by the individuals concerned, and for that reason alone (if altruism is not enough) solutions are needed. Professor Rutter has no easy answers to offer (any more than did Professor Donald 
Court's committee ${ }^{2}$ or the $\mathrm{WHO}^{3}$ ), but his suggestions, though low key, deserve serious attention from politicians as well as academics.

The frequency of adolescent disorders depends, he says, on four variables, each of which is amenable to intervention. Firstly, individual predisposition is affected by genetic influences and the environment in which the child is brought up. Counselling and psychotherapy have proved disappointing in countering such disadvantages, and Rutter's conclusion is that priority must be given to prevention: preventing unwanted births, especially to teenage and single women, by expanding family planning programmes, and reducing the frequency of organic brain dysfunction by improving the obstetric and neonatal paediatric services. Continuity of good quality parenting is another vital factor-and he is quite specific on this point: "in the case of young children whose parents seem unlikely ever to be able to look after them at all adequately, an early decision should be taken with respect to adoption or long term tostering." And all teenagers, he believes, should be encouraged to learn about caring by helping to look after younger children, the sick and lonely, and old people.

The second variable is the social environment, and in particular schools and housing. Again Rutter speaks plainly: a selective system of schooling may well have advantages for the $15 \%$ of children in the academic élite, but it almost certainly has great disadvantages for the $85 \%$ of children in the non-academic schools. The outcome for pupils is known to be worse, and delinquency more frequent, in schools with a high proportion of intellectually less able children. Ideally every school should have a balance of abilities close to the national average among its intake: unfortunately no easy way has yet been found to achieve this. In the long run, Rutter suggests, the solution may be to ensure that communities are sufficiently socially mixed so that community schools would get this ideal reasonable balance of intakes. Such a pattern would also help to reduce the stresses on children of being brought up in areas with above-average densities of disadvantaged families.

Thirdly, some of the deviant behaviour of adolescence could be prevented by specific interventions. Rutter lists making alcohol less readily available by raising its price and restricting licensing hours; persuading doctors to reduce levels of prescribing to lessen the availability of drugs for selfpoisoning; making more use of school premises for leisure activities; and improving standards of maintenance of public buildings - a proved method of reducing the frequency of vandalism.

Fourthly, adolescent behaviour is amenable to influence by the health services for children-if their quality is good enough. Here Rutter echoes a theme familiar to $B M \mathcal{Y}$ readers: "those clinicians engaged in therapeutic services should include a good proportion of the more experienced . . . it cannot be right that a profession [nursing] whose raison d'être is personal care should heavily penalise those individuals who wish to continue in the work for which they were trained ... . Much the same issues apply to social work." Adolescents ought, he says, to be able to refer themselves for help, and opportunities for consultation should be available wherever teenagers work and meet.

Is this degree of concern with teenage problems justified, sceptics may ask, especially at a time of economies in public spending? Professor Rutter quotes consistent evidence that serious personal, psychiatric, and psychosocial troubles are more frequent in adults whose behaviour was persistently antisocial during adolescence. Thus intervention is warranted, with effective monitoring of its outcome-and the same is true of the response of the penal system to adolescent offenders. No one grand strategy will provide all the answers: a variety of treatment methods and social policies need to be tried and assessed. Rutter's final, and sobering, thought is that more has not been done already largely because of the resistance to change attributable to professional self-interest, political dogma, and financial constraints.

1 Rutter, Michael, Changing Youth in a Changing Society. The Rock Carling Fellowship 1979. London, Nuffield Provincial Hospitals Trust, 1979, £7.50.

2 DHSS, Fit for the Future. Report of the Committee on Child Health Services (chairman S D M Court). London, HMSO, 1976.

${ }^{3}$ World Health Organisation, Child Mental Health and Psychosocial Development: report of a WHO Expert Committee. WHO Technical Report Series no 613. Geneva, World Health Organisation, 1977.

\section{Mass eating}

One of the most devastating replies to a bedside inquiry after the wellbeing of a patient is, "When I get home and get some good food I'll be much better, thank you, doctor." Good food has two meanings, good to eat and good nutritionally, and some institutional meals are neither. Yet with the kinds of food available in the Western world the two are synonymous. It is extremely difficult to select an attractive and palatable menu that does not at the same time supply the nutrients required.

Why, then, if it is so easy to obtain the required nutrients from the wide variety of available foods are there so many complaints about institutional catering-school meals, hospital meals (in both the ward and the dining room) and meals in refectories and canteens? Probably because our wants are so diverse (one man's mince is another man's slop) and because the limitations of facilities and staff and the inevitably severe restrictions of cost call for the highest skills by the catererand the call remains unanswered.

The critic's cleaver should not be wielded indiscriminately. Those eating in a few institutions, including some hospitals, boast of the high quality of the food they get, but these appear to be the exceptions. Food is an easy target but too often it is a justified target. The low esteem in which school meals are held may be on a par with mother-in-law jokes, but evaluations have shown most of them to be inadequate in quantity quite apart from the opinion of the school gourmets. Hospital meals are expected to tempt the sick palate, but again all too often they fail objective tests.

We have recently complained ${ }^{1}$ that some parts of our hospitals are little cleaner than the worst of our railway stations-a comment that can be linked with a report of food poisoning in hospitals. ${ }^{2}$ In a wartime pamphlet ${ }^{3}$ a Minister of Health stated "a good kitchen superintendent makes a healthier and happier hospital, and experience has often showed that the better the feeding the less the cost." We have learnt a lot about hygiene, nutrition, and people's wants in the past 40 years but have not applied the knowledge. The consumer does not complain (even the critical school child finally gives up); the doctor is not aware; but does the caterer care?

\footnotetext{
${ }^{1}$ British Medical fournal, 1979, 2, 952.

2 Thomas, M, et al, Lancet, 1977, 1, 1046.

3 War-time Feeding in Hospitals. London, Ministry of Health, 1942.
} 